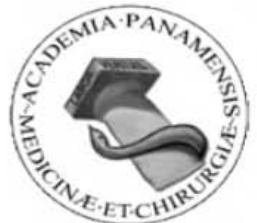

Caso de interés radiológico

\title{
Necrosis Avascular De La Cabeza Humeral.
}

\author{
Avascular Necrosis Of The Humeral Head. \\ *Simons Michael. \\ ${ }^{*}$ Radiólogo. Complejo Hospitalario Metropolitano. Caja de Seguro Social. Panamá.
}

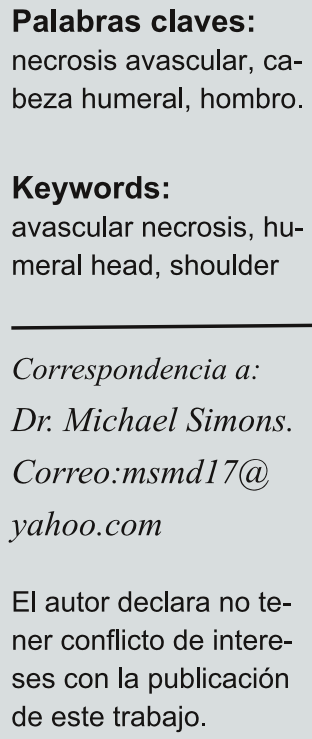

\section{Resumen}

La necrosis avascular de la cabeza humeral es el segundo sitio más común de presentación de esta patología. Los hallazgos radiográficos son inespecíficos y el diagnóstico final se basa en la Resonancia magnética. La medicina nuclear queda como una segunda opción de no contar con resonancia.

\section{Abstract}

The avascular necrosis of the humeral head is the second most common site of presentation of this pathology. The radiographic findings are nonspecific and the final diagnosis is based on Magnetic Resonance. Nuclear medicine remains a second option.

\section{CASO CLÍNICO}

Paciente femenina de 36 años con antecedente de anemia falciforme que acude a consulta de ortopedia por dolor y limitación funcional en el hombro izquierdo. La paciente es referida para realización de rayos $\mathrm{X}$ del hombro y resonancia magnética para descartar patología del manguito de los rotadores.

\section{DISCUSIÓN}

La osteonecrosis de la cabeza humeral también es conocida como la enfermedad de Hass. Es el segundo lugar más común en presentarse. El lugar más común es la pelvis.

Usualmente se presenta en la región subcondral del hueso. En algunos casos puede llegar al colapso del hueso necrótico subcondral y posterior osteoartritis severa. Hay un centro de necrosis, rodeado por un área de isquemia. Los factores de riesgo más comunes son el uso de corti- coides, trauma, las hemoglobinopatías, el embarazo, radioterapia, enfermedades del tejido conectivo, pancreatitis, gota, uso de alcohol y trasplante renal.

\section{Características Radiográficas:}

El estadio inicial es la disminución de la densidad ósea (osteopenia). Gradualmente hay micro fracturas del hueso subcondral, el cual no se puede reparar. Posterior a esto la corteza colapsa y pasa a los cambios degenerativos.

La Resonancia Magnética es la modalidad con mayor sensibilidad.

En Resonancia magnética el signo más temprano es el edema difuso. Posterior a esto se identifica una línea reactiva focal de baja señal con centro graso. Más tarde aparece el signo del doble contorno, el cual es diagnóstico y se observa una línea de baja señal y otra de mayor señal. Por último hay cambios degenerativos severos.

La medicina nuclear es la segunda opción si no contamos con el beneficio de la Resonancia Magnética. 
Figura 1. Se identifica esclerosis de la cabeza humeral con pequeños osteofitos y formaciones quísticas subcondrales. El espacio articular está conservado. No hay calcificaciones patológicas

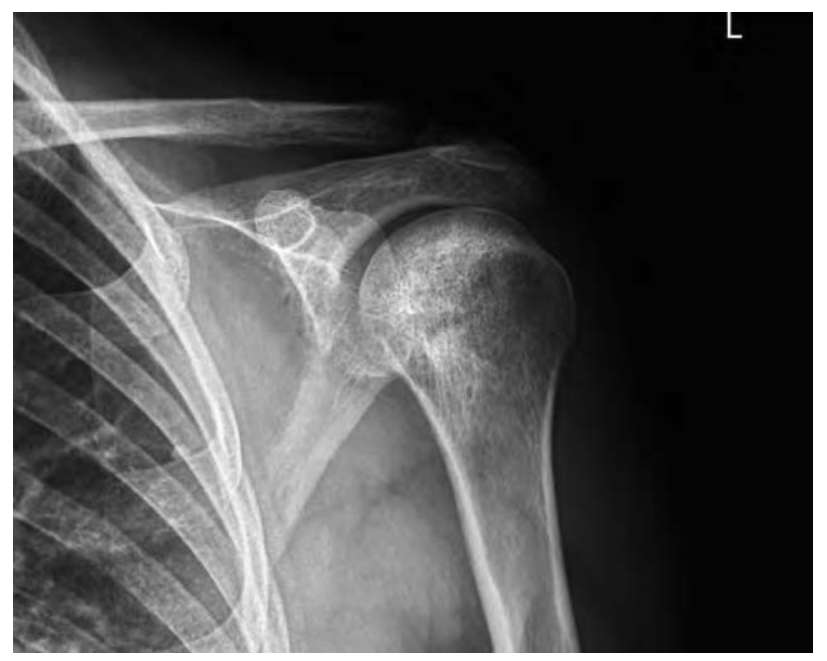

Figura 2. Imagen potenciada en T1 en el plano coronal. Se observa esclerosis de la cabeza humeral.

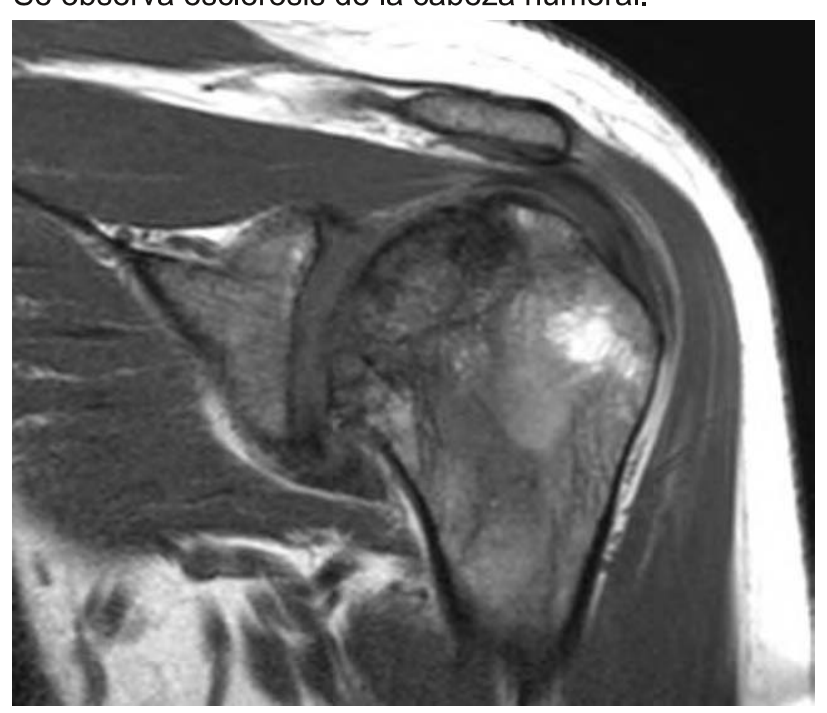

\section{REFERENCIAS}

[1] Dines JS, Strauss EJ, Fealy S, Craig EV. Arthroscopic-assisted core decompression of the humeral head. Arthroscopy. 2007; 23: 103.e1-4.

[2] Wheeless CR, Marchant MH Jr, Stubbs A, Basamania CJ. Osteonecrosis of the Humeral Head. Wheeless Textbook of Orthopaedic. April 52011.

[3] D.J. Burgess, M.S. McGrath, P.M. Bonutti, D.R. Marker,r.E. Delanois, M.A. Mont "Shoulder Resurfacing" J Bone Joint Surg Am 2009;91:1228-38
Fig. 3, 4,5: Imágenes potenciadas en T2 en los tres planos en donde se observa edema, cambios degenerativos y el signo del doble contorno. Hallazgos compatibles con osteonecrosis de la cabeza humeral.

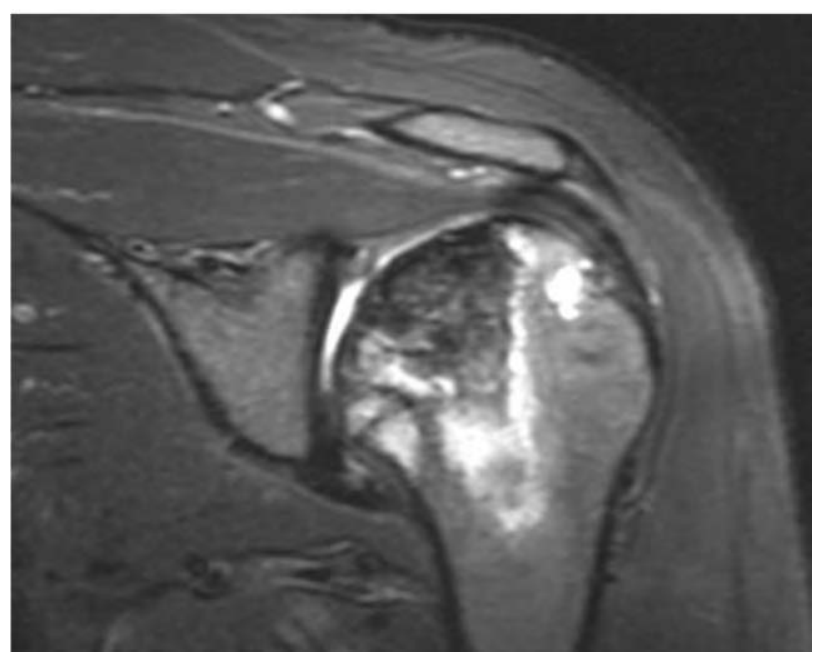

Figura 4. Imágenes potenciadas en T2 en los tres planos

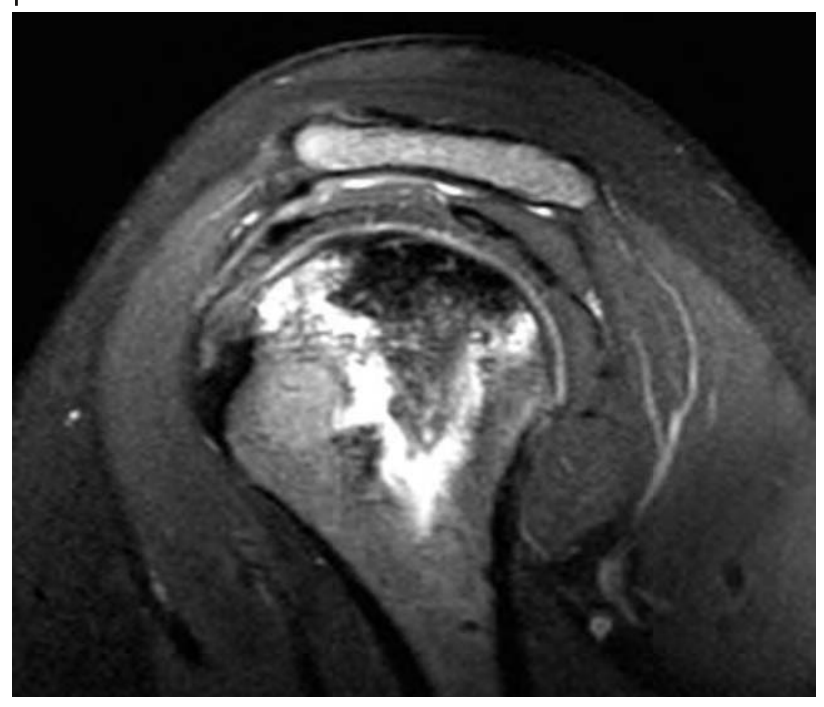

Figura 5. Imágenes potenciadas en T2 en los tres planos

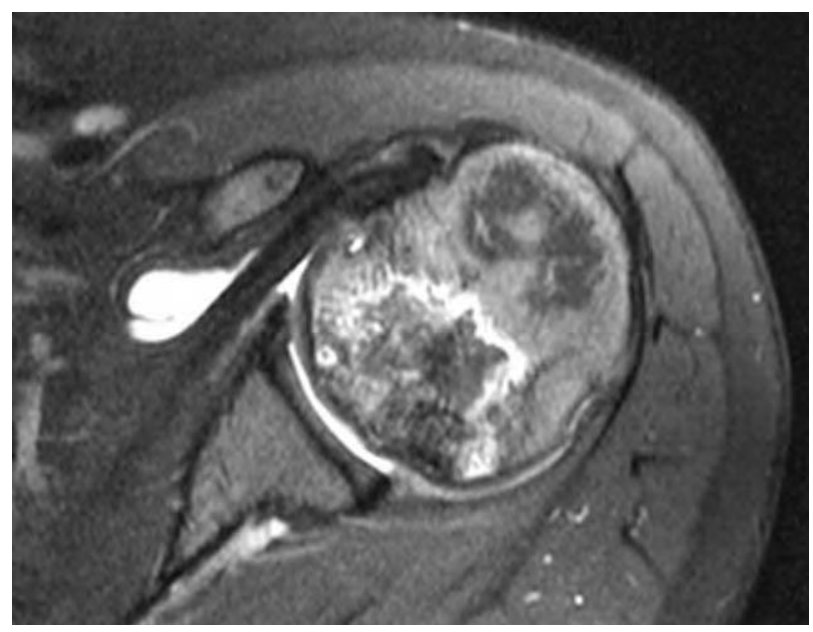

